\title{
Cervical vertebroplasty for osteolytic metastases as a minimally invasive therapeutic option in oncological surgery: outcome in 14 cases
}

\author{
${ }^{*}$ Martin Stangenberg, MD, ${ }^{1}$ Lennart Viezens, MD, ${ }^{2}$ Sven O. Eicker, MD, PhD, ${ }^{3}$ Malte Mohme, MD, ${ }^{3}$ \\ Klaus C. Mende, MD, ${ }^{3}$ and Marc Dreimann, MD ${ }^{1}$
}

Departments of ${ }^{1}$ Trauma, Hand and Reconstructive Surgery, and ${ }^{3}$ Neurosurgery, University Hospital Hamburg-Eppendorf, Hamburg; and 'Department of Trauma Surgery, Orthopedics and Plastic Surgery, University Hospital Goettingen, Germany

OBJECTIVE The treatment of cervical spinal metastases represents a controversial issue regarding the type, extent, and invasiveness of interventions. In the lumbar and thoracic spine, kypho- and vertebroplasties have been established as minimally invasive procedures for patients with metastases to the vertebral bodies and without neurological deficit. These procedures show good results with respect to pain reduction and low complication rates. However, limited data are available for kypho- and vertebroplasties for cervical spinal metastases. In an effort to add to existing data, the authors here present a case series of 14 patients who were treated for osteolytic metastases of the cervical spine using vertebroplasty alone or in addition to another surgical procedure involving the cervical spine in a palliative setting to reduce pain and restore stability.

METHODS Fourteen patients consisting of 8 males and 6 females, with a mean age of 64.7 years (range 44-85 years), were treated with vertebroplasty at the authors' clinic between January 2015 and November 2016. In total, 25 vertebrae were treated with vertebroplasty: 10 C-2, 5 C-3, 2 C-4, 2 C-5, 3 C-6, and 3 C-7. Two patients had an additional posterior stabilization and 5 patients an additional anterior stabilization. In 13 cases, the surgical approach was a modified SmithRobinson approach; in 1 case, the cement was injected into the corpus axis from posteriorly. Patients with osteolytic defects of the posterior wall of the vertebral body did not undergo surgery, nor did patients with neurological deficits. Preoperatively, on the 2nd day after surgery, and at the follow-up, neck pain was rated using the visual analog scale (VAS).

RESULTS Twelve patients were examined at follow-up (mean 9 months). Neck pain was rated as a mean of 6.0 (range 3-8) preoperatively, 2.9 on Day 2 after surgery (range $0-5$ ), and 0.5 at the follow-up (range $0-4$ ), according to the VAS. The mean Neck Disability Index at follow-up was 3.6\% (range 0\%-18\%).

CONCLUSIONS Anterior vertebroplasty of the cervical spine via an anterolateral approach represents a safe and minimally invasive procedure with a low complication rate and appears suitable for reducing pain and restoring stability in cases of cervical spinal metastases. Vertebroplasties can be combined with other anterior and posterior operations of the cervical spine and, in the axis vertebra, can be performed transpedicularly from posteriorly. Thus, in cases in which the posterior wall of the vertebral body is intact, vertebroplasty represents a less invasive alternative to vertebral replacement in oncological surgery. Prospective randomized trials with a longer follow-up period and a larger patient cohort are needed to confirm the encouraging results of this case series.

https://thejns.org/doi/abs/10.3171/2017.5.FOCUS17175

KEY WORDS vertebroplasty; cervical metastasis; osteolysis; tumor; minimally invasive surgery

$\mathrm{T}$ HE skeletal system is the third most common site affected by metastases, ranking after the lung and liver. The spine is involved most often; $70 \%$ of patients with metastasizing cancer show spinal metastases at the time of death. The thoracic and lumbar spine are most frequently affected, whereas cervical metastases occur in $8 \%-15 \%$ of patients. ${ }^{11,21}$

With the progress in cancer therapy and consequent increased life expectancy, the incidence of spinal metastases and the need to treat them also rise. ${ }^{20,43}$ In itself, the

* Drs. Stangenberg and Viezens contributed equally to this work. 
patient's age does not represent a fundamental contraindication to a surgical procedure. On the contrary, in the presence of an indication, early surgical intervention is recommended because the rate of emergency surgery increases in patients with progressive tumor. It logically follows that in these progressive tumor cases, complication rates would rise and patient outcomes would be worse. ${ }^{1}$

Different prognostic scores have been developed to help the physician in therapeutic decision making for patients with metastases of the thoracic and lumbar spine, taking into account the number of spinal metastases, the grade of malignancy, the primary site of the cancer, the patient's general condition, the presence or absence of neurological deficits, and the extent of other bony or visceral metastases. ${ }^{17,47,48}$ The literature shows that surgery can improve pain and quality of life in patients with spinal metastases..$^{9,38}$

Associations between the size and location of the metastatic lesion and the impending collapse of the vertebral body were statistically analyzed by Taneichi et al. to estimate the critical point of collapse. ${ }^{46}$ Knowledge of the risk factors and the predicted probability of vertebral collapse is widely used when making a therapeutic decision regarding thoracic and lumbar spinal metastases.

To date, however, no studies have focused on the same issue in cervical spinal metastases; their treatment remains controversial in terms of the type, extent, and invasiveness of therapeutic interventions. Treatment options besides single, adjuvant, and neoadjuvant chemo- and radiotherapy include vertebrectomy with vertebral body replacement, spinal decompression surgery, and ventral or dorsal spondylodesis. The main objectives of cervical tumor treatment are pain reduction, stabilization of the cervical spine to avoid the collapse of vertebral bodies, and an improvement in or the preservation of life quality. In accordance with the primarily palliative therapeutic concept, together with multiple comorbidities and reduced life expectancy, the extent and invasiveness of surgical interventions should be as limited as possible.

Since Galibert and Deramond first described vertebroplasty in 1987, both kypho- and vertebroplasties in the lumbar and thoracic spine have been widely established as minimally invasive procedures for patients with metastases to the vertebral bodies and without neurological deficit. ${ }^{19}$ These procedures show good to very good results with respect to pain reduction and low complication rates. ${ }^{6,22,31}$ Besides the stabilizing effect of injected bone cement, it is well-known that the heat produced during cement polymerization damages tumor cells and leads to tumor necrosis..$^{30,36,40}$ However, limited data on kypho- and vertebroplasties for cervical spinal metastases are available.

In an effort to add to existing data, we present a case series of 14 patients who were treated for osteolytic metastases of the cervical spine using vertebroplasty alone or in addition to another surgical procedure of the cervical spine. If necessary, we also performed hybrid operations with ventral or dorsal spondylodesis. Indications for surgery were osteolysis that was considered unstable and/ or the presence of neck pain. Metastases were considered unstable if more than $50 \%$ of the vertebral body was af- fected by the osteolysis. According to Taneichi et al., vertebrae of the lumbar and thoracic spine are associated with a dramatically increased risk of imminent pathological fracture if more than $50 \%$ of the vertebral body excluding the dorsal structures is affected. ${ }^{46}$ If the pedicles are also involved, the risk increases if 20\%-25\% (lumbar) or $35 \%-40 \%$ (thoracic) of the vertebral body is osteolytic.

The vertebrae in this study that were treated with vertebroplasty showed, except in 1 patient (Case 11), no destruction of the dorsal structures, but more than $50 \%$ of the vertebral body was affected in every case.

\section{Methods}

Fourteen patients (8 males and 6 females) with metastatic disease of the cervical spine were treated using cervical vertebroplasty between January 2015 and November 2016 at our clinic. The indication for the surgical procedure was confirmed in each case by an interdisciplinary tumor board. The mean patient age was 64.7 years (range $44-85$ years); the mean body mass index was $24.3 \mathrm{~kg} / \mathrm{m}^{2}$ (range $17.3-31.9 \mathrm{~kg} / \mathrm{m}^{2}$ ). The primary tumor was myeloma in 10 cases, breast carcinoma in 2, and pulmonary cancer in 1. One patient had cancer of unknown primary origin at the time of surgery; histopathological examination during surgery revealed the presence of gastric carcinoma.

In total, 25 vertebrae were treated with vertebroplasty: 10 C-2, 5 C-3, 2 C-4, 2 C-5, 3 C-6, and 3 C-7. Two patients underwent additional dorsal stabilization and 5 patients additional ventral stabilization of the cervical spine. In 13 cases, the surgical approach was a modified Smith-Robinson approach; in 1 case, cement was injected into the corpus axis from posteriorly. Patients with osteolytic defects of the posterior wall of the vertebral body did not undergo vertebroplasty, nor did patients with neurological deficits.

In all cases, preoperative diagnostics included radiography, multislice CT, and MRI to detect possible spinal compression. Preoperatively, on Day 2 after surgery, and at the follow-up examination, pain was rated using a visual analog scale (VAS) with values from 0 (no pain) to 10 (maximum pain). At the time of follow-up, the Neck Disability Index (NDI) questionnaire was administered. . $^{41,50,51}$ On Day 2 after surgery and at the follow-up, anteroposterior and lateral radiographs of the cervical spine were obtained, as were multislice CT scans of the cervical spine in cases that were difficult to assess.

In 8 cases, single-level vertebroplasties were performed; patients in the other 6 cases received bone cement in multiple vertebrae. In 4 patients, the corpus axis was augmented with cement and an additional anterior odontoid screw was used to achieve more stability. Two patients underwent a hybrid operation with additional posterior stabilization of the upper cervical spine. In 1 case, vertebroplasties of C-2, C-3, and C-5 and a vertebrectomy of C-4 with vertebral body replacement were performed and an anterior plate from C-3 to C-6 was implanted. Five patients underwent kyphoplasties and/or spondylodesis with tumor decompression of the thoracic and lumbar spine, performed in the same operative session.

For the anterior operations, a modified Smith-Robinson approach to the cervical spine was used. The proce- 


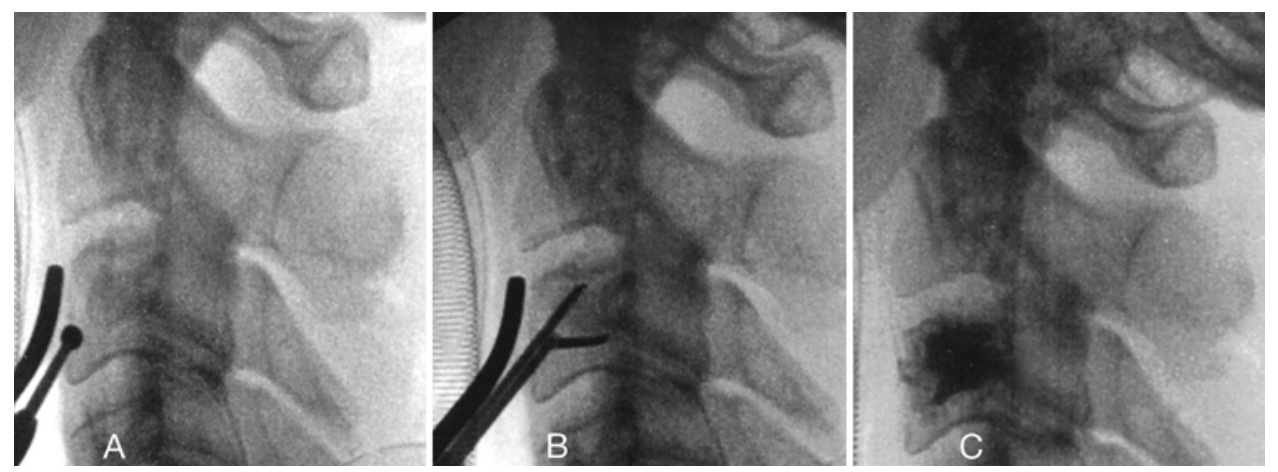

FIG. 1. Intraoperative fluoroscopic images, lateral projection, showing opening of the anterior vertebral body wall of C-3 with a drill (A), removal of the tumor mass and creation of a resection cavity using forceps (B), and the vertebral body filled with bone cement after the procedure $(\mathbf{C})$.

dure was performed in the operating room using a $\mathrm{C}$-arm imaging system for biplanar control (Arcadis Orbic 3D, Siemens Healthcare). All patients were informed about the potential dangers of, the alternatives to, and the expected outcomes of the procedure and signed informed consent.

The course of the operation in the case of the vertebroplasties was as follows: After nasal intubation and the induction of general anesthesia, prophylactic single-shot antibiotic therapy (cefuroxime $1.5 \mathrm{~g}$ ) was injected intravenously. The patient was placed supine with slight extension of the cervical spine in a head cup on the operating table, and the operating field was disinfected and draped. The correct cervical level was marked using a lateral radiograph, and the skin was incised horizontally left to the midline for approximately $2-4 \mathrm{~cm}$, depending on the number of levels that needed to be reached. The platysma muscle was severed at the anterior border of the sternocleidomastoid muscle, and blunt dissection was performed with careful conservation of the esophageal-tracheal bundle and the carotid sheath. When the prevertebral cervical fascia was reached, under fluoroscopic control, a blunt dissector was used to mark the correct cervical vertebra. After confirmation of the correct level, the anterior cortical bone of the vertebral body was opened with a diamond drill. The soft tissue of the osteolysis was carefully removed from the vertebral body using forceps and a sharp spoon and was submitted for histopathological examination. Afterward, a Jamshidi needle (10-gauge, 150-mm length) was placed centrally with the tip in the cavity of the vertebral body; $9.4 \mathrm{ml}$ of liquid methylmethacrylate monomer was mixed with $20 \mathrm{ml}$ of methylmethacrylate polymer powder (Mendec Spine HV System, Tecres Medical). The high-viscosity bone cement was drawn into a 5-ml syringe and, after reaching the correct consistency, was carefully injected under low pressure into the vertebral body through the placed Jamshidi needle. The needle was pulled back slowly while the cement was injected to attain complete filling of the cavity. The injection was performed under intermittent biplanar fluoroscopic control to avoid leakage of the cement into the adjacent soft tissues, spinal canal, and vertebral artery. If multiple vertebrae were affected, each vertebral body was prepared and, one directly after another in quick succession, was filled with cement. Subsequently, the needle was removed and the surgical site was irrigated with saline solution. A drain was inserted and the wound closed. Relevant steps of the procedure are shown in Fig. 1.

In Cases 3, 4, 13, and 14, the anterior odontoid screw was placed first and then the cement was injected through a hole drilled into the vertebral body of the axis. In Case 9 , the vertebrectomy with vertebral body replacement was performed first and the holes for the anterior cervical plate (Reflex Hybrid, Stryker) were drilled. Then, bone cement was placed through the drilled holes into the vertebral bodies of C-2, C-3, and C-5, and the screws (and the plate) were quickly placed and tightened during the hardening time. In Case 11, a large osteolysis of more than half of the axis including the dorsal structures was present, so we decided to first perform a dorsal spondylodesis via a median dorsal standard approach from C-1 to C-4 (Synapse, DePuy Synthes). Subsequently, a Jamshidi needle was placed transpedicularly from the right side into the vertebral body of C-2 and the cement was injected under biplanar fluoroscopic control.

After the procedure, all patients were transferred to an intermediate care station for 1 night and were mobilized with a soft cervical brace, which was used for 10-12 days until wound healing was completed. Demographic and procedural data are summarized in Table 1.

\section{Results}

Twelve of 14 patients could be examined at follow-up. Four weeks after surgery, 1 patient with myeloma died of severe sepsis after the induction of chemotherapy; contact with another patient was lost. In all cases, the histopathological result confirmed the underlying primary tumor. In the patient with cancer of unknown primary origin (Case 11), we detected gastric adenocarcinoma.

We had 3 main surgical groups plus 2 other operations: 1) 1-level vertebroplasty (4 cases), 2 ) multilevel vertebroplasty (4 cases), and 3 ) vertebroplasty plus odontoid screw placement (4 cases). The mean surgery time for Group 1 was 46 minutes (range 35-55 minutes); for Group 2, 53 minutes (range 37-65 minutes); and for Group 3, 66 minutes (range 57-72 minutes). Two cases could not be classified into any of these surgical groups: Case 9 with 131 
TABLE 1. Demographic and procedural data in 14 patients with cervical spinal metastases

\begin{tabular}{|c|c|c|c|c|c|c|c|c|}
\hline $\begin{array}{l}\text { Case } \\
\text { No. }\end{array}$ & $\begin{array}{l}\text { Age (yrs)/ } \\
\text { Sex }\end{array}$ & Level of VP & Procedure & $\begin{array}{l}\text { Cement per } \\
\text { VB }(\mathrm{ml})\end{array}$ & Primary Origin & $\begin{array}{c}\mathrm{BMl} \\
\left(\mathrm{kg} / \mathrm{m}^{2}\right)\end{array}$ & $\begin{array}{l}\text { Op Time } \\
\text { (mins) }\end{array}$ & $\begin{array}{l}\text { Radiation Time } \\
\text { for VP (sec) }\end{array}$ \\
\hline 1 & $74 / M$ & $\begin{array}{l}\text { C-2, C-3, } \\
\quad \text { C-4 }\end{array}$ & $\begin{array}{l}\text { VP plus pst transarticular fusion } \\
\text { C1-2 (Magerl technique) }\end{array}$ & $1.7,1.9,2.1$ & Myeloma & 25.9 & $\begin{array}{l}65 \text { ventral, } \\
85 \text { dorsal }\end{array}$ & NA \\
\hline 2 & $72 / \mathrm{M}$ & C-2 & $\begin{array}{l}\text { VP plus dorsal thoracolumbar } \\
\text { spondylodesis T10-L2 }\end{array}$ & 2 & Myeloma & 24.4 & $\begin{array}{l}46 \text { ventral, } \\
135 \text { dorsal }\end{array}$ & NA \\
\hline 3 & $44 / \mathrm{M}$ & $\mathrm{C}-2$ & VP plus odontoid screw & 1.8 & Myeloma & 29.4 & 68 & NA \\
\hline 4 & $69 / F$ & $\mathrm{C}-2, \mathrm{C}-3$ & VP plus odontoid screw & $1.9,2.3$ & Myeloma & 25.6 & 72 & NA \\
\hline 5 & $62 / F$ & C-2 & $\begin{array}{l}\text { VP plus dorsal thoracic kypho- } \\
\text { plasty T-4 \& T-11 }\end{array}$ & 1.5 & Breast cancer & 27.6 & $\begin{array}{l}46 \text { ventral, } \\
65 \text { dorsal }\end{array}$ & NA \\
\hline 6 & $45 / M$ & $\begin{array}{l}\text { C-2, C-3, } \\
\text { C-6 }\end{array}$ & $\begin{array}{l}\text { VP plus dorsal thoracolumbar } \\
\text { spondylodesis T12-L3 }\end{array}$ & $1.4,1.6,2.4$ & Myeloma & 17.5 & $\begin{array}{l}61 \text { ventral, } \\
219 \text { dorsal }\end{array}$ & NA \\
\hline 7 & $48 / F$ & C-6, C-7 & VP & $1.9,2.1$ & Breast cancer & 21.2 & 37 & 10 \\
\hline 8 & $74 / M$ & C-7 & $\begin{array}{l}\text { VP plus dorsal thoracic kypho- } \\
\text { plasty T-8, T-11, T-12 \& dorsal } \\
\text { lumbar spondylodesis L2-5 }\end{array}$ & 2.1 & Myeloma & 25.8 & $\begin{array}{l}55 \text { ventral, } \\
223 \text { dorsal }\end{array}$ & NA \\
\hline 9 & $76 / M$ & $\begin{array}{l}\mathrm{C}-2, \mathrm{C}-3 \\
\mathrm{C}-5\end{array}$ & $\begin{array}{l}\text { VP w/ vertebrectomy C-4 \& } \\
\text { ventral plate C3-6 }\end{array}$ & $1.8,1.9,2.6$ & Myeloma & 24.5 & 131 & NA \\
\hline 10 & $62 / M$ & C-3 & VP & 1.5 & Myeloma & 17.3 & 35 & 10 \\
\hline 11 & $67 / M$ & $\mathrm{C}-2$ & $\begin{array}{l}\text { VP from dorsal plus dorsal } \\
\text { spondylodesis C1-4 }\end{array}$ & 1.7 & $\begin{array}{l}\text { CUPO, later determined } \\
\text { to be gastric cancer }\end{array}$ & 23.8 & 113 & NA \\
\hline 12 & $84 / F$ & $\begin{array}{l}\text { C-4, C-5, } \\
\text { C-6, C-7 }\end{array}$ & VP & $\begin{array}{r}1.8,1.9 \\
1.9,2.0\end{array}$ & Pulmonary cancer & 22.9 & 47 & 15 \\
\hline 13 & $44 / F$ & $\mathrm{C}-2$ & $\begin{array}{l}\text { VP plus odontoid screw \& dorsal } \\
\text { lumbar kyphoplasty L-3 }\end{array}$ & 2.2 & Myeloma & 31.9 & $\begin{array}{l}65 \text { ventral, } \\
31 \text { dorsal }\end{array}$ & NA \\
\hline 14 & $85 / F$ & $\mathrm{C}-2$ & VP plus odontoid screw & 2.1 & Myeloma & 21.9 & 57 & NA \\
\hline Mean & 64.7 & & & 1.9 & & 24.26 & & 11.7 \\
\hline
\end{tabular}

$\mathrm{BMI}=$ body mass index CUPO = cancer of unknown primary origin; $\mathrm{NA}=$ not available; pst = posterior; $\mathrm{VB}=$ vertebral body; $\mathrm{VP}=$ vertebroplasty.

minutes and Case 11 with 113 minutes. Case 4 matched 2 groups but was assigned to Group 3 .

After normal wound healing, or 10 days postoperatively, patients could be started on local radiation or adjuvant chemotherapy. The minimally invasive nature of our procedure allows for a relatively short healing interval after surgery; thus, the risk of impaired wound healing is re-
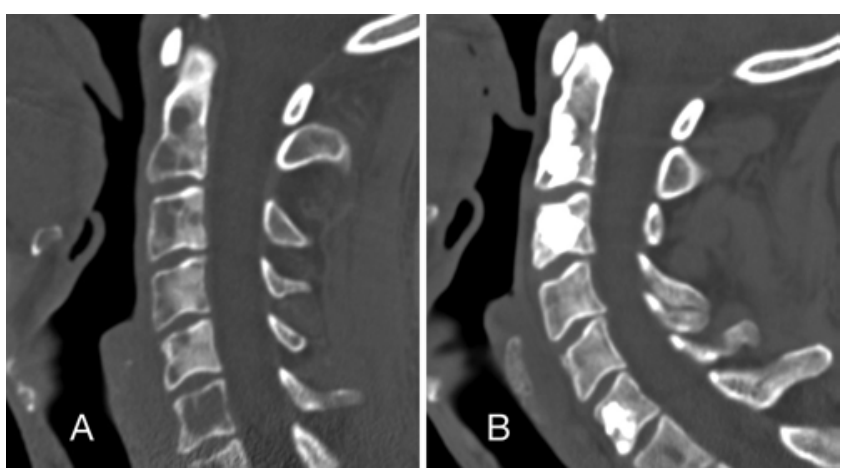

FIG. 2. Case 6. Preoperative sagittal CT scans showing large osteolytic defects of the C-2, C-3, and C-6 vertebral bodies and smaller lesions that were considered stable in C-4 and C-5 (A). Postoperatively, there was good cement distribution in the affected vertebrae (B). duced, as compared to such risks with other more invasive techniques.

Neck pain preoperatively was 6.0 on the VAS (range $3-8$ ); on Day 2 after surgery, 2.9 (range $0-5$ ); and at follow-up, 0.5 (range 0-4). The NDI at follow-up was 3.6\% (range 0\%-18\%). All patients could reduce their use of analgesic drugs or discontinue them.

The mean amount of bone cement used was $1.9 \mathrm{ml}$ per vertebra (range 1.2-2.6). Radiologically, good cement distribution and filling of the resection cavity was demonstrated in all cases (Fig. 2), but 1 patient had cement leakage anterolaterally from the vertebral body of C-4 (Fig. 3) and another patient experienced cement leakage dorsally into the spinal canal, although it did not cause relevant stenosis (Fig. 4). Both cases were asymptomatic. Radiographic control images at follow-up showed unchanged implant positioning without adjacent fractures or instabilities. There were no other intra- or postoperative complications apart from the death of the patient in Case 10 , which was not an immediate consequence of surgery. Esophageal or tracheal perforations, spinal or nerve root damage, and lacerations of the carotid artery and jugular veins were not observed. Thus, the total complication rate was $8 \%$ per vertebra and $14 \%$ per patient.

Neurological examination results for all patients were unchanged between the pre- and postoperative periods. 

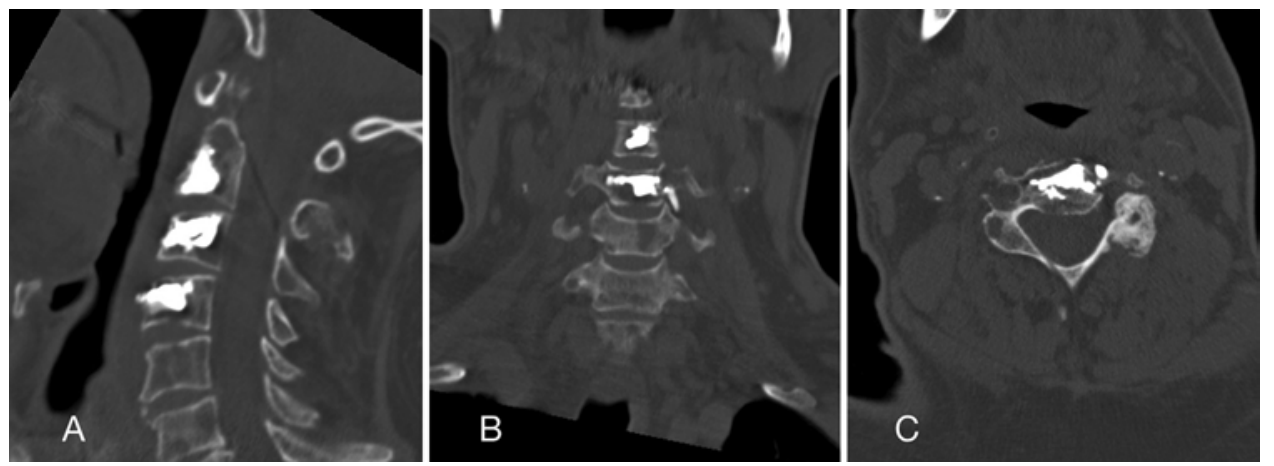

FIG. 3. Case 1. Sagittal (A), coronal (B), and axial (C) CT scans showing left-sided anterolateral cement extravasation at C-4.

The mean follow-up was 9 months (range 2-20 months). Mean radiation time intraoperatively was 11.7 seconds in the 3 cases in which only cervical vertebroplasties were performed. In the other cases, data are not available because additional radiographs were obtained for the other procedures and only the total radiation time was documented. Clinical outcome parameters and complications are summarized in Table 2.

\section{Discussion}

Anterior vertebroplasty of the cervical spine represents a secure, minimally invasive procedure with a low complication rate for osteolytic metastases. It is effective for reducing pain and restoring stability, can easily be combined with other ventral or dorsal procedures of the cervical spine, and, in the axis vertebra, can be performed from posteriorly. Vertebroplasty of the cervical spine thus represents a minimally invasive alternative to the far more invasive vertebrectomy with vertebral body replacement and anterior spondylodesis. To perform the vertebroplasty, the posterior wall of the vertebral body should be intact to avoid potentially dangerous complications such as intraspinal leakage with a risk of high para- or tetraparesis.

Apart from the standard anterolateral approach, which was described by Southwick in 1957 and Smith and Robinson in $1958,{ }^{42,44}$ different percutaneous approaches for cervical vertebrae C3-7 have been described in the literature. For the atlas and axis vertebrae, transoral, postero-
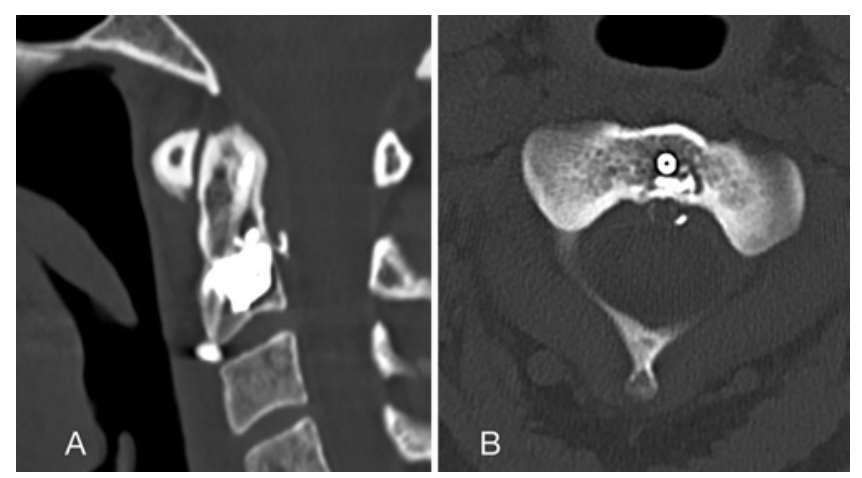

FIG. 4. Case 11. Sagittal (A) and axial (B) CT scans showing intraspinal cement extravasation at $\mathrm{C}-2$. lateral, anterior retropharyngeal, and even percutaneous transdiscal approaches have been used for vertebroplasty. $7,10,12,13,39,53$ The standard anterolateral Smith-Robinson approach that we used represents secure surgical access to the anterior cervical spine and has the advantage of an initial incision of approximately $2-3 \mathrm{~cm}$ that can be easily extended to reach more than 1 or 2 cervical vertebrae. Vertebrae C-2 to T-1 can be easily reached via this anterior approach.

The 2 cement leakages in this study represent the only complications and fortunately were completely asymptomatic. Nevertheless, surgeons should be aware that even if the posterior wall of the vertebral body on the preoperative CT scan appears to be intact, epidural-intraspinal cement leakage could occur (Fig. 4). It could lead to compression of the upper spinal cord with consequent high tetraparesis or even a fatal outcome. Embolization of

TABLE 2. Summary of clinical outcome data in 14 patients with cervical spinal metastases

\begin{tabular}{lcccccl}
\hline $\begin{array}{c}\text { Case } \\
\text { No. }\end{array}$ & $\begin{array}{c}\text { FU } \\
\text { (mos) }\end{array}$ & $\begin{array}{c}\text { Preop } \\
\text { VAS }\end{array}$ & $\begin{array}{c}\text { Postop } \\
\text { VAS }\end{array}$ & $\begin{array}{c}\text { FU } \\
\text { VAS }\end{array}$ & $\begin{array}{c}\text { FU NDI } \\
(\%)\end{array}$ & \multicolumn{1}{c}{ Complications } \\
\hline 1 & 11 & 6 & 4 & 4 & 18 & $\begin{array}{c}\text { Asymptomatic cement } \\
\text { leakage anterolat }\end{array}$ \\
\hline 2 & 20 & 8 & 5 & 0 & 2 & None \\
\hline 3 & 9 & 7 & 3 & 0 & 2 & None \\
\hline 4 & 9 & 6 & 3 & 2 & 0 & None \\
\hline 5 & 14 & 6 & 4 & 0 & 4 & None \\
\hline 6 & 6 & 3 & 0 & 0 & 0 & None \\
\hline 7 & 11 & 6 & 3 & 0 & 0 & None \\
\hline 8 & 7 & 6 & 3 & 0 & 0 & None \\
\hline 9 & 6 & 7 & 5 & 0 & 4 & None \\
\hline 10 & NA & 6 & 3 & NA & NA & NA \\
\hline 11 & 5 & 7 & 5 & 0 & 10 & None \\
\hline 12 & 7 & 4 & 1 & 0 & 4 & None \\
\hline 13 & 5 & 5 & 2 & 0 & 0 & Asymptomatic cement \\
& & & & & & leakage dorsal \\
\hline 14 & NA & 7 & 0 & NA & NA & NA \\
\hline Mean & 8.8 & 6 & 2.9 & 0.5 & 3.6 & \\
\hline
\end{tabular}

$\mathrm{FU}=$ follow-up; $\mathrm{NA}=$ not applicable. 
bone cement through the epidural or paravertebral venous plexus is also conceivable and could lead to a pulmonary embolism. This complication occurs relatively often in vertebroplasties and kyphoplasties of the thoracic and lumbar spine, with rates ranging from $2.1 \%$ to $26 \% .^{2,8,16}$, 24,49,52 Embolization via the arterial circulation of the vertebral artery into the posterior brain circulation has been described in 1 case and led to cerebellar symptoms and lateral homonymous hemianopia after the vertebroplasty. Imaging in this case revealed an acute cerebellar and occipital infarction due to a cement embolism of the vertebral artery. ${ }^{35}$ Furthermore, cement leakages into the neuroforamina with nerve root compression and into the cervical disc space can occur. ${ }^{15}$

To prevent cement leakage and embolization, the cement should have an adequate consistency, a high-resolution fluoroscopic device should be used, and, most importantly, the injection should be stopped immediately if leakage is recognized. ${ }^{33}$

The rate of cement leakage for percutaneous vertebroplasty of the thoracic and lumbar spine has been reported as $41 \%$ up to $88 \%$, and for percutaneous kyphoplasty, between $9 \%$ and $49 \% .^{23,27}$ For cervical vertebroplasty, cement leakage rates between $3 \%$ and $58 \%$ can be found in the literature, though the overall number of reported cases in the cervical spine is far smaller. ${ }^{15}$ It should be noted that in addition to leakage of the cement itself into the spinal canal, there is also a risk of tumor displacement into the canal when the cement is injected, which could also create spinal cord or nerve root compression. Consequently, if the tumor mass already extends into the spinal canal, injecting cement should be avoided. ${ }^{4}$

We performed low-pressure filling of the vertebral body and first resected the tumor mass using a sharp spoon or forceps before filling the resection cavity with cement, as described by Floeth et al..$^{18}$ The risks associated with a conventional percutaneous pressure-directed technique are considered to be higher in terms of cement leakage and displacement of the tumor mass toward potentially dangerous structures, compared with the risks of the alternative low-pressure technique we used. In addition, evidence suggests that the use of high-viscosity bone cement may reduce the leakage rates in vertebroplasty and kyphoplasty, which is why we used it. ${ }^{3,26}$ Furthermore, possible ventral and ventrolateral cement leakages can be detected under direct vision and removed instantaneously after the injection, which is not possible in percutaneous procedures.

Volumetric studies of the cervical spine have determined the vertebral body volume of $\mathrm{C}-2$ to be $6.3 \pm 1.1$ $\mathrm{cm}^{3}, \mathrm{C}-3$ as $10.4 \pm 1.9 \mathrm{~cm}^{3}, \mathrm{C}-4$ as $10.5 \pm 2.0 \mathrm{~cm}^{3}$, C-5 as $11.1 \pm 2.1 \mathrm{~cm}^{3}$, C-6 as $12.4 \pm 2.5 \mathrm{~cm}^{3}$, and C-7 as $15.4 \pm$ $2.8 \mathrm{~cm}^{3} \cdot{ }^{14}$ In our study, the volume of the vertebral body filled with bone cement at C-2 was, on average, $28.7 \%$ (total amount injected: number of cases $=$ average amount per vertebral body; $18.1 \mathrm{ml}: 10=1.81 \mathrm{ml})$; at C-3, $16.6 \%$ ( $9.2 \mathrm{ml}: 5=1.84 \mathrm{ml})$; at C-4, $18.6 \%$ (3.9 ml: $2=1.95 \mathrm{ml}$ ); at C-5, 20.3\% (4.5 ml: $2=2.25 \mathrm{ml})$; at C-6, $16.7 \%$ (6.2 ml: $3=2.07 \mathrm{ml})$; and at C-7, $13.4 \%(6.2 \mathrm{ml}: 3=2.07 \mathrm{ml})$. In biomechanical studies of the thoracic and lumbar spine, it has been shown that the minimal amount of bone ce- ment necessary to restore adequate stability or stiffness, respectively, ranges between $13 \%$ and $16 \%$ of the vertebral body volume..$^{28,29,33}$ Similar studies of the cervical spine do not exist, to our knowledge. The amounts of cement used in the present study are therefore in line with the biomechanical recommendations for adequate stress distribution after vertebroplasty.

The duration of fluoroscopy for vertebroplasties alone was very limited in this minimally invasive technique, with an average of 12 seconds, which reduces the radiation exposure of the patient and medical personnel in the operation room. The amount of radiation exposure in percutaneous procedures of the cervical spine is not documented in the literature but is likely to be higher than in the technique we used.

Even though the patient sample and the operative procedures in our study were inhomogeneous, we can show that a short operation time can be achieved for single-level and multilevel vertebroplasties, as well as for vertebroplasties with an additional odontoid screw. The average surgery time of 46 minutes for single-level vertebroplasty is slightly lower than that described in the literature: Floeth et al. reported a surgery time of 51 minutes; Cianfoni et al., 60 minutes; Kordecki et al., 67 minutes; and Brage et al., using a transoral approach, 90 minutes..$^{710,18,25}$ Comparable data do not exist for multilevel vertebroplasty and vertebroplasty with an odontoid screw; our average surgery times for the respective procedures were 53 and 66 minutes. Compared with the far more invasive and elaborate vertebrectomy with vertebral body replacement, which may have been an alternative because of the large bony defects encountered, these times still represent a relatively short period for the procedure.

Intraoperative blood loss was not monitored but was seen to be low for the vertebroplasties alone and, of course, higher when combined with other procedures involving the cervical spine.

The primary treatment goals of stabilization of the cervical spine and effective pain control were achieved in all patients. The preoperative pain value of $6.0 / 10$ on the VAS was comparable to scores in other published studies, as were the postoperative values (2.9/10) at Day 2 after surgery and at the follow-up (0.5/10). $5,18,32,37,45$ We showed that this significant reduction in neck pain occurred despite having performed in the cervical spine additional dorsal procedures in 2 cases and additional ventral procedures in 5 cases.

We acknowledge the limitations of this observational study, such as the relatively short follow-up, the nonprospective study design, and the small number of treated patients. There was no control group because conservative treatment of the osteolysis had failed, patients had significant pain, and we considered the affected vertebrae to be unstable and at high risk for vertebral collapse.

\section{Conclusions}

Our study suggests that in selected patients with osteolysis of the cervical spine, vertebroplasty via an anterior approach and low-pressure cement application can be performed with immediate pain relief, a consequent reduc- 
tion in analgesic drug use, and a low complication rate. The possibility of combining the technique with other procedures involving the cervical spine makes it a very practicable option in oncological surgery. In the future, prospective randomized trials will need to show whether the encouraging results of this case series can endure for a longer period in a larger patient cohort. In that event, it should be noted that the maximum time of follow-up would be limited by the palliative situation. Finally, it must be emphasized that in this palliative setting, an individual and interdisciplinary therapeutic concept should always be discussed among the surgeon, oncologist, radiation therapist, and patient.

\section{References}

1. Amelot A, Balabaud L, Choi D, Fox Z, Crockard HA, Albert $\mathrm{T}$, et al: Surgery for metastatic spine tumors in the elderly. Advanced age is not a contraindication to surgery! Spine $\mathbf{J}$ 17:759-767, 2017

2. Anselmetti GC, Corgnier A, Debernardi F, Regge D: Treatment of painful compression vertebral fractures with vertebroplasty: results and complications. Radiol Med (Torino) 110:262-272, 2005

3. Anselmetti GC, Zoarski G, Manca A, Masala S, Eminefendic $\mathrm{H}$, Russo F, et al: Percutaneous vertebroplasty and bone cement leakage: clinical experience with a new high-viscosity bone cement and delivery system for vertebral augmentation in benign and malignant compression fractures. Cardiovasc Intervent Radiol 31:937-947, 2008

4. Barr JD, Mathis JM: Extreme vertebroplasty: techniques for treating difficult lesions, in Mathis JM, Deramond H, Belkoff SM (ed): Percutaneous Vertebroplasty and Kyphoplasty. New York: Springer, 2006, pp 185-196

5. Blondel B, Adetchessi T, Demakakos J, Pech-Gourg G, Dufour $\mathrm{H}$, Fuentes S: Anterolateral kyphoplasty in the management of cervical spinal metastasis. Orthop Traumatol Surg Res 98:341-345, 2012

6. Bouza C, López-Cuadrado T, Cediel P, Saz-Parkinson Z, Amate JM: Balloon kyphoplasty in malignant spinal fractures: a systematic review and meta-analysis. BMC Palliat Care 8:12, 2009

7. Brage L, Roldán H, Plata-Bello J, Martel D, García-Marín V: Transoral vertebroplasty for a C2 aneurysmal bone cyst. Spine J 16:e473-e477, 2016

8. Choe DH, Marom EM, Ahrar K, Truong MT, Madewell JE: Pulmonary embolism of polymethyl methacrylate during percutaneous vertebroplasty and kyphoplasty. AJR Am J Roentgenol 183:1097-1102, 2004

9. Choi D, Fox Z, Albert T, Arts M, Balabaud L, Bunger C, et al: Prediction of quality of life and survival after surgery for symptomatic spinal metastases: a multicenter cohort study to determine suitability for surgical treatment. Neurosurgery 77:698-708, 2015

10. Cianfoni A, Distefano D, Chin SH, Varma AK, Rumboldt Z, Bonaldi G: Percutaneous cement augmentation of a lytic lesion of $\mathrm{C} 1$ via posterolateral approach under $\mathrm{CT}$ guidance. Spine J 12:500-506, 2012

11. Ciftdemir M, Kaya M, Selcuk E, Yalniz E: Tumors of the spine. World J Orthop 7:109-116, 2016

12. Clarençon F, Cormier E, Pascal-Moussellard H, Maldent JB, Pichon S, Le Jean L, et al: Transoral approach for percutaneous vertebroplasty in the treatment of osteolytic tumor lesions of the lateral mass of the atlas: feasibility and initial experience in 2 patients. Spine (Phila Pa 1976) 38:E193E197, 2013

13. Cohen M, Zeitoun D, Blanpain S, Brochard C, Lellouche J, Deramond H: Percutaneous vertebroplasty of the $\mathrm{C} 2$ body and dens using the anterior oblique ascending transdiscal approach. J Neuroradiol 40:211-215, 2013

14. Crawford B, Kim DG, Moon ES, Johnson E, Fields HW, Palomo JM, et al: Cervical vertebral bone mineral density changes in adolescents during orthodontic treatment. Am J Orthod Dentofacial Orthop 146:183-189, 2014

15. De la Garza-Ramos R, Benvenutti-Regato M, Caro-Osorio E: Vertebroplasty and kyphoplasty for cervical spine metastases: a systematic review and meta-analysis. Int J Spine Surg 10:7, 2016

16. Duran C, Sirvanci M, Aydoğan M, Ozturk E, Ozturk C, Akman C: Pulmonary cement embolism: a complication of percutaneous vertebroplasty. Acta Radiol 48:854-859, 2007

17. Fisher CG, DiPaola CP, Ryken TC, Bilsky MH, Shaffrey CI, Berven $\mathrm{SH}$, et al: A novel classification system for spinal instability in neoplastic disease: an evidence-based approach and expert consensus from the Spine Oncology Study Group. Spine (Phila Pa 1976) 35:E1221-E1229, 2010

18. Floeth FW, Herdmann J, Rhee S, Turowski B, Krajewski K, Steiger HJ, et al: Open microsurgical tumor excavation and vertebroplasty for metastatic destruction of the second cervical vertebra-outcome in seven cases. Spine J 14:3030-3037, 2014

19. Galibert P, Deramond H, Rosat P, Le Gars D: [Preliminary note on the treatment of vertebral angioma by percutaneous acrylic vertebroplasty.] Neurochirurgie 33:166-168, 1987 (Fr)

20. Guillevin R, Vallee JN, Lafitte F, Menuel C, Duverneuil NM, Chiras J: Spine metastasis imaging: review of the literature. J Neuroradiol 34:311-321, 2007

21. Hage WD, Aboulafia AJ, Aboulafia DM: Incidence, location, and diagnostic evaluation of metastatic bone disease. Orthop Clin North Am 31:515-528, vii, 2000

22. Health Quality Ontario: Vertebral augmentation involving vertebroplasty or kyphoplasty. Ont Health Technol Assess Ser 16:1-202, 2016

23. Hulme PA, Krebs J, Ferguson SJ, Berlemann U: Vertebroplasty and kyphoplasty: a systematic review of 69 clinical studies. Spine (Phila Pa 1976) 31:1983-2001, 2006

24. Kim YJ, Lee JW, Park KW, Yeom JS, Jeong HS, Park JM, et al: Pulmonary cement embolism after percutaneous vertebroplasty in osteoporotic vertebral compression fractures: incidence, characteristics, and risk factors. Radiology 251:250-259, 2009

25. Kordecki K, Lewszuk A, Puławska-Stalmach M, Michalak P, Łukasiewicz A, Sackiewicz I, et al: Vertebroplasty of cervical vertebra. Pol J Radiol 80:51-56, 2015

26. Lador R, Liberman S, Ben-Galim P, Dreiangel N, Reitman CA, Hipp JA: A cadaver study to compare vertebral augmentation with a high-viscosity cement to augmentation with conventional lower-viscosity cement. J Spinal Disord Tech 26:68-73, 2013

27. Lee IJ, Choi AL, Yie MY, Yoon JY, Jeon EY, Koh SH, et al: CT evaluation of local leakage of bone cement after percutaneous kyphoplasty and vertebroplasty. Acta Radiol 51:649654,2010

28. Liebschner MA, Rosenberg WS, Keaveny TM: Effects of bone cement volume and distribution on vertebral stiffness after vertebroplasty. Spine (Phila Pa 1976) 26:1547-1554, 2001

29. Luo J, Daines L, Charalambous A, Adams MA, AnnesleyWilliams DJ, Dolan P: Vertebroplasty: only small cement volumes are required to normalize stress distributions on the vertebral bodies. Spine (Phila Pa 1976) 34:2865-2873, 2009

30. Malawer MM, Dunham W: Cryosurgery and acrylic cementation as surgical adjuncts in the treatment of aggressive (benign) bone tumors. Analysis of 25 patients below the age of 21. Clin Orthop Relat Res (262):42-57, 1991

31. Markmiller M: Percutaneous balloon kyphoplasty of malig- 
nant lesions of the spine: a prospective consecutive study in 115 patients. Eur Spine J 24:2165-2172, 2015

32. Masala S, Anselmetti GC, Muto M, Mammucari M, Volpi T, Simonetti G: Percutaneous vertebroplasty relieves pain in metastatic cervical fractures. Clin Orthop Relat Res 469:715-722, 2011

33. Mathis JM: Percutaneous vertebroplasty: complication avoidance and technique optimization. AJNR Am J Neuroradiol 24:1697-1706, 2003

34. Molloy S, Mathis JM, Belkoff SM: The effect of vertebral body percentage fill on mechanical behavior during percutaneous vertebroplasty. Spine (Phila Pa 1976) 28:1549-1554, 2003

35. Mont'Alverne F, Vallée JN, Cormier E, Guillevin R, Barragan $\mathrm{H}$, Jean $\mathrm{B}$, et al: Percutaneous vertebroplasty for metastatic involvement of the axis. AJNR Am J Neuroradiol 26:1641-1645, 2005

36. Nelson DA, Barker ME, Hamlin BH: Thermal effects of acrylic cementation at bone tumour sites. Int J Hyperthermia 13:287-306, 1997

37. Pflugmacher R, Schleicher P, Schröder RJ, Melcher I, Klostermann CK: Maintained pain reduction in five patients with multiple myeloma 12 months after treatment of the involved cervical vertebrae with vertebroplasty. Acta Radiol 47:823829, 2006

38. Quan GMY, Vital JM, Aurouer N, Obeid I, Palussière J, Diallo A, et al: Surgery improves pain, function and quality of life in patients with spinal metastases: a prospective study on 118 patients. Eur Spine J 20:1970-1978, 2011

39. Rodriguez-Catarino M, Blimark C, Willén J, Mellqvist UH, Rödjer S: Percutaneous vertebroplasty at C2: case report of a patient with multiple myeloma and a literature review. Eur Spine J 16 (Suppl 3):242-249, 2007

40. San Millán Ruíz D, Burkhardt K, Jean B, Muster M, Martin JB, Bouvier J, et al: Pathology findings with acrylic implants. Bone 25 (2 Suppl):85S-90S, 1999

41. Serlin RC, Mendoza TR, Nakamura Y, Edwards KR, Cleeland CS: When is cancer pain mild, moderate or severe? Grading pain severity by its interference with function. Pain 61:277-284, 1995

42. Smith GW, Robinson RA: The treatment of certain cervicalspine disorders by anterior removal of the intervertebral disc and interbody fusion. J Bone Joint Surg Am 40-A:607-624, 1958

43. Sohn S, Kim J, Chung CK, Lee NR, Park E, Chang UK, et al: A nationwide epidemiological study of newly diagnosed spine metastasis in the adult Korean population. Spine J 16:937-945, 2016

44. Southwick WO, Robinson RA: Surgical approaches to the vertebral bodies in the cervical and lumbar regions. J Bone Joint Surg Am 39-A:631-644, 1957

45. Sun G, Wang LJ, Jin P, Liu XW, Li M: Vertebroplasty for treatment of osteolytic metastases at $\mathrm{C} 2$ using an anterolateral approach. Pain Physician 16:E427-E434, 2013

46. Taneichi H, Kaneda K, Takeda N, Abumi K, Satoh S: Risk factors and probability of vertebral body collapse in metastases of the thoracic and lumbar spine. Spine (Phila Pa 1976) 22:239-245, 1997

47. Tokuhashi Y, Matsuzaki H, Oda H, Oshima M, Ryu J: A revised scoring system for preoperative evaluation of metastatic spine tumor prognosis. Spine (Phila Pa 1976) 30:2186-2191, 2005

48. Tomita K, Kawahara N, Kobayashi T, Yoshida A, Murakami H, Akamaru T: Surgical strategy for spinal metastases. Spine (Phila Pa 1976) 26:298-306, 2001

49. Venmans A, Klazen CAH, Lohle PNM, van Rooij WJ, Verhaar HJJ, de Vries J, et al: Percutaneous vertebroplasty and pulmonary cement embolism: results from VERTOS II. AJNR Am J Neuroradiol 31:1451-1453, 2010

50. Vernon H: The Neck Disability Index: state-of-the-art, 19912008. J Manipulative Physiol Ther 31:491-502, 2008

51. Vernon H, Mior S: The Neck Disability Index: a study of reliability and validity. J Manipulative Physiol Ther 14:409415, 1991

52. Wang LJ, Yang HL, Shi YX, Jiang WM, Chen L: Pulmonary cement embolism associated with percutaneous vertebroplasty or kyphoplasty: a systematic review. Orthop Surg 4:182-189, 2012

53. Yang JS, Chu L, Xiao FT, Zhang DJ, Wang Y, Chen L, et al: Anterior retropharyngeal approach to $\mathrm{C} 1$ for percutaneous vertebroplasty under C-arm fluoroscopy. Spine J 15:539545,2015

\section{Disclosures}

The authors report no conflict of interest concerning the materials or methods used in this study or the findings specified in this paper.

\section{Author Contributions}

Conception and design: Dreimann. Acquisition of data: Stangenberg, Viezens. Analysis and interpretation of data: Stangenberg. Drafting the article: Stangenberg. Critically revising the article: Viezens, Mende, Mohme, Dreimann. Approved the final version of the manuscript on behalf of all authors: Stangenberg. Statistical analysis: Stangenberg. Study supervision: Eicker, Dreimann.

\section{Correspondence}

Martin Stangenberg, University Hospital Hamburg-Eppendorf, Martinistr. 52, Hamburg D-20246, Germany. email: m.stangenberg@uke.de. 